\title{
Prognostic significance of hypoxia inducible factor-1 $\alpha$ expression in patients with clear cell renal cell carcinoma
}

\author{
SHUIQING WU ${ }^{1}$, FEN JIANG ${ }^{2}$, HONGTAO WU $^{1}$, YINHUAI WANG ${ }^{1}$, RAN XU $^{1}$, JIAN CAO ${ }^{1}$, \\ QIONG $\mathrm{LU}^{3}$, XUAN ZHU ${ }^{1}$, ZHAOHUI ZHONG ${ }^{1}$ and XIAOKUN ZHAO ${ }^{1}$ \\ ${ }^{1}$ Department of Urology, The Second Xiangya Hospital, Central South University, Changsha, \\ Hunan 410008, P.R. China; ${ }^{2}$ Pharmacogenomics Research Center, Inje University College of \\ Medicine, Busan, South Gyeongsang 47392, Republic of Korea; ${ }^{3}$ Department of Pharmacy, \\ The Second Xiangya Hospital, Central South University, Changsha, Hunan 410008, P.R. China
}

Received March 16, 2017; Accepted November 23, 2017

DOI: $10.3892 / \mathrm{mmr} .2018 .8409$

\begin{abstract}
The prognostic significance of hypoxia inducible factor- $1 \alpha(\mathrm{HIF}-1 \alpha)$ expression in tumors and the levels of preoperative hemoglobin in clear cell renal cell carcinoma (ccRCC), with or without concomitant chronic obstructive pulmonary disease (COPD), was investigated. A total of 128 patients with ccRCC who underwent surgery were analyzed using retrospective methods. Overall survival (OS) and progression free survival (PFS) were analyzed with clinicopathological variables, including preoperative hemoglobin levels, COPD and the levels of HIF-1 $\alpha$ expression, by Kaplan-Meier survival analysis. Levels of HIF-1 $\alpha$ expression were detected by immunohistochemistry and the multivariate analysis was performed by proportional hazards regression. High levels of HIF-1 $\alpha$ expression were associated with a higher pathological stage and histological grade in patients with ccRCC $(\mathrm{P}<0.05)$. The median OS and PFS of patients with concomitant COPD were shorter compared with patients without $\mathrm{COPD}(\mathrm{P}<0.05)$. The levels of serum hemoglobin, HIF-1 $\alpha$ expression and COPD diagnosis were all identified as independent prognostic variables for the OS and PFS of patients with ccRCC.
\end{abstract}

\section{Introduction}

Out of the total estimated new cases of cancer, the occurrence of renal carcinomas ranked 7th in men and 10th in women in 2017 (1). Clear cell renal cell carcinoma (ccRCC) is the most common type of renal carcinomas. Over the past few decades, the incidence of renal cell carcinoma has increased by $2-3 \%$

Correspondence to: Dr Ran Xu, Department of Urology, The Second Xiangya Hospital, Central South University, 139 Renmin Road, Changsha, Hunan 410008, P.R. China

E-mail: xuran@csu.edu.cn

Key words: hypoxia, chronic obstructive pulmonary disease, hypoxia inducible factor- $1 \alpha$, hemoglobin, clear cell renal cell carcinoma per decade, particularly in developed countries $(2,3)$. In 2012, an estimated 144,000 patients died from renal cancer, which was $1.7 \%$ of the estimated number of total cancer-associated mortalities worldwide (3). If diagnosed at an early stage, $60 \%$ of patients with renal cell carcinoma are estimated to have a low risk of cancer-specific mortality. However, following therapy, $\sim 30 \%$ of patients exhibit recurrence with a poor prognosis (4). Therefore, it is important to investigate the factors associated with ccRCC, in order to improve its management.

Hypoxic conditions have been identified in several types of solid tumors. Hypoxia promotes anaerobic metabolism, angiogenesis and relevant genes expression, such as connective tissue growth factor (CTGF), osteopontin (OPN) and interleukin-6 (IL-6) in solid tumors, which are typically associated with poor prognosis (5). Acute hypoxia may inhibit cellular proliferation and induce apoptosis in tumor cells. However, in a chronic hypoxic environment, tumor cells may adapt through alterations to an intricate regulatory network of transcription factors and associated proteins, leading to cellular multiplication, migration and bioactivity $(6,7)$.

Overexpression of hypoxia inducible factor-1 $\alpha$ (HIF-1 $\alpha)$ has been identified to be a common characteristic of several types of solid tumors, and numerous studies have linked its elevated levels to poor prognosis, angiogenesis and tumor metastasis $(8,9)$. HIF-1 $\alpha$ overexpression is thought to be an adaptive response to hypoxic stimulation in the tumor microenvironment and is associated with the activation of a number of survival pathways (10). Chronic obstructive pulmonary disease (COPD) is a chronic hypoxic condition of the respiratory system that is characterized by persistent and progressive airflow limitation. Low levels of hemoglobin have been linked with elevated HIF-1 $\alpha$ expression in COPD (11). Similar events may occur in ccRCC and contribute to its poor prognosis.

\section{Materials and methods}

Patients. A total of 128 patients aged 35-85 (mean age, 61.5) years, diagnosed with ccRCC by pathological examination between November, 2006 and December, 2015 at The Second Xiangya Hospital (Changsha, China), were enrolled. Of the participants, 96 patients were male and 32 were female, with 
69 patients undergoing a full nephrectomy, and 59 patients undergoing a partial nephrectomy. The basic clinicopathological characteristics were collected for further analysis, such as R.E.N.A.L scores (Radius, Exophytic/endophytic, Nearness to collecting system or sinus, Anterior/posterior, Location relative to polar lines) (12), TNM stages (tumor size, lymph node status and metastasis) (13), Fuhrman grades (Fuhrman 1 and Fuhrman 2 were merged as G1, Fuhrman 3 was considered as G2, and Fuhrman 4 was classified as G3) (14), and so on. All enrolled patients were followed-up according to their individual characteristics. Follow-up typically consisted of a urine cytology assessment and abdominal ultrasound every 3 months in the first 2 years, every 6 months in the following 2 years and yearly thereafter. A chest and abdominal computed tomography scan was performed every year in the first 5 years following surgery. Informed consent was obtained from all participants and approval for the present study was given by the ethics committee of The Second Xiangya Hospital of Central South University.

Assessment of COPD and the preoperative hemoglobin. Patients with COPD were diagnosed by a chest physician. The diagnosis was based on respiratory symptoms and spirometric assessment of airflow obstruction, with or without a history of risk factor exposure. Hemoglobin levels were determined by routine venous blood examinations prior to surgery and patients were split into three groups: $>120,100-120$ and $<100 \mathrm{~g} / 1$.

Immunohistochemistry. Postoperative renal carcinoma tissues were fixed in $10 \%$ neutral buffered formalin for $24 \mathrm{~h}$ at room temperature, and washed thoroughly with PBS. Following conventional dehydration, tissues were embedded in molten paraffin and kept at $4^{\circ} \mathrm{C}$. The paraffin-embedded tissues were cut into $5-\mu \mathrm{m}$ thick sections on poly-L-lysine coated glass slides using a microtome. Following $2 \mathrm{~h}$ of heat-drying $\left(55^{\circ} \mathrm{C}\right)$, serial sections were deparaffinized in xylene and a descending ethanol series $(100,90,80$ and $70 \%$ ethanol). Circles were drawn on the slides around the tissues using a hydrophobic barrier pen iprior to placing the sections in moderate sodium citrate buffer (pH 6.0) in a microwave oven. The slides were boiled for $3 \mathrm{~min}$ in microwave (SHARP) at full power and subsequently maintained at a sub-boiling temperature for 5 min with $30 \%$ power. Slides were washed with PBS and subsequently blocked with $5 \%$ bovine serum albumin (Sigma-Aldrich; Merck KGaA, Darmstadt, Germany) for $30 \mathrm{~min}$ at room temperature. Sections were incubated overnight at $4^{\circ} \mathrm{C}$ with anti-HIF-1 $\alpha$ monoclonal antibody (Mab H1a67, IgG2b isotype; cat. no. MS-1164-P0; diluted 1:100; Thermo Fisher Scientific, Inc., Waltham, MA, USA). Next day, following three washes with PBS, the paraffin-embedded sections were stained using an Elivision Super HRP Immunohistochemistry Kit (cat. no. KIT-9931, Maixin Bio, Inc., Fujian, China), and the second antibody was included in this kit (reagent B, high sensitive enzyme labelled anti-mouse), $50 \mu \mathrm{l}$ per slide at room temperature for $30 \mathrm{~min}$, with $1 \%$ diaminobenzidine and counterstaining with hematoxylin for $5 \mathrm{~min}$ at room temperature.

Expression of HIF-1 $\alpha$ was semi-quantitatively assessed by two blinded independent reviewers. HIF-1 $\alpha$ expression was interpreted and scored in the tumor region. A total of six randomly-selected fields throughout the entire section at $\mathrm{x} 400$ magnification were analyzed, and 200 cells were counted by two different operators in each field. The expression of HIF-1 $\alpha$ was graded as follows:,$-<1 \%$ positive cells; $1+, 1-10 \%$ positive cells; $2+, 10-50 \%$ positive cells; and $3+,>50 \%$ positive cells.

Statistical analysis. Data analysis was performed using SPSS version 19.0 (IBM Corp., Armonk, NY, USA). Kaplan-Meier survival curve is a non-parametric statistic method used to estimate the survival influence with lifetime data in different patients, and Kaplan-Meier survival curves were constructed and analyzed using GraphPad prism 6 (GraphPad Software, Inc., La Jolla, CA, USA). $\mathrm{P}<0.05$ was considered to indicate a statistically significant difference. All P-values were two-sided. The significance of the results was assessed using Student's t-tests, one-way analysis of variance, followed by Tukey post hoc, and $\chi^{2}$ tests. The hazard ratio (HR) and $95 \%$ confidence interval of the HR was calculated using the Cox proportional hazard model.

\section{Results}

Patient characteristics. Table I presents the detailed characteristics of the patients. A total of 92 patients were classified as stage T1-T2 and 36 patients were classed as stage T3-T4. The number of patients classified as Fuhrman grade G1was 69; $\mathrm{G} 2,40$ and $\mathrm{G} 3,19$. A total of 30 patients were diagnosed with ccRCC and COPD. The clinicopathological characteristics of patients with or without COPD are presented in Table II. There was no significant difference detected in age, pathological stages, R.E.N.A.L Scores, types of surgery or comorbidity between patients with or without COPD. However, Fuhrman grades, pulmonary function, smoking history, C-reactive protein levels, serum hemoglobin levels and HIF-1 $\alpha$ expression were significantly different between patients with or without COPD.

As presented in Table III, a significant difference was detected between HIF-1 $\alpha$ expression levels and pathological stages or Fuhrman grades of ccRCC $(\mathrm{P}<0.001$ and $\mathrm{P}=0.002$, respectively), indicating that elevated $\mathrm{HIF}-1 \alpha$ expression levels were associated with higher TNM stages and Fuhrman grades in ccRCC.

Survival analysis. The median overall survival (OS) was 50.2 months for the COPD group and 62.5 months for the no COPD group (Table IV). Progression free survival (PFS) was 22.2 months for the COPD group and 45.0 months for the no COPD group. This difference was statistically significant $(\mathrm{P}<0.001)$. The median OS for the patients whose preoperative hemoglobin counts were $>120,100-120$ and $<100 \mathrm{~g} / 1$ was 66.4, 54.1 and 43.5 months, respectively. The median PFS for the patients grouped as above was 53.6, 38.0 and 24.2 months, respectively. Analysis between the groups indicated a statistically significant result $(\mathrm{P}<0.05)$. The median $\mathrm{OS}$ for the patients with HIF-1 $\alpha$ expression levels defined as '-', '+', '++' and '+++' was 71.2, 62.5, 54.2 and 42.1 months, respectively. The median PFS for the patients grouped as above was 51.0, 42.5, 30.2 and 20.5 months, respectively. Analysis between these groups additionally indicated a statistically significant result $(\mathrm{P}<0.05)$. As presented in Table IV, the median OS and 
Table I. Patient characteristics $(n=128)$.

\begin{tabular}{lc}
\hline Mean age, years & $61.6(35-85)$ \\
\hline Sex & \\
Male & $96(75.0 \%)$ \\
Female & $32(25.0 \%)$ \\
Affected kidney & \\
Right & $68(53.1 \%)$ \\
Left & $60(46.9 \%)$ \\
Furhman grade & \\
Good & $69(53.9 \%$ \\
Moderate & $40(31.3 \%)$ \\
Poor & $19(14.8 \%)$ \\
Pathological stage & \\
T1-T2 & $92(71.9 \%)$ \\
T3-T4 & $36(28.9 \%)$ \\
Smoking history & \\
Smoking index $\leq 400$ & $86(67.2 \%)$ \\
Smoking index $>400$ & $42(32.8 \%)$ \\
COPD & $30(23.4 \%)$ \\
Other comorbidities & \\
Hypertension & $32(25.0 \%)$ \\
Diabetes mellitus & $18(14.1 \%)$ \\
Coronary disease & $12(9.4 \%)$ \\
Tuberculosis & \\
Mean serum haemoglobin, g/l & \\
\hline
\end{tabular}

COPD, chronic obstructive pulmonary disease.

PFS were significantly different depending on pathological stage, histological grade and R.E.N.A.L Score (Table IV). The multivariate Cox proportional hazard model of variables is presented in Table $\mathrm{V}$. These results indicated that pathological stage, R.E.N.A.L score, COPD diagnosis and HIF-1 $\alpha$ expression were independent prognostic variables for OS and PFS. The preoperative levels of hemoglobin were an independent prognostic variable for PFS only. The OS and PFS for patients calculated with respect to hemoglobin, COPD and HIF-1 $\alpha$ levels were depicted by Kaplan-Meier survival curves (Figs. 1-3), which indicated low preoperative hemoglobin $(<100 \mathrm{~g} / \mathrm{l})$, COPD status and high levels of HIF-1 $\alpha$ expression in tumor $(+++)$ were significantly associated with poor OS and PFS in ccRCC patients (all $\mathrm{P}<0.05$ ).

\section{Discussion}

Hypoxia is commonly observed in various tumor types and is typically associated with poor prognosis. A number of studies have demonstrated that hypoxic conditions are associated with tumor glycolysis, angiogenesis and prognosis, and hypoxic conditions can induce and regulate tumor metastasis $(6,15)$. Therefore, interfering with hypoxia may be an effective approach to preventing or reducing the growth and metastasis of tumours, as well as improving patient prognosis $(5,16)$. Certain diseases, including anemia and
Table II. Clinicopathological characteristics and COPD incidence.

\begin{tabular}{|c|c|c|c|c|c|}
\hline \multirow[b]{2}{*}{ Characteristics } & \multicolumn{2}{|c|}{ No COPD } & \multicolumn{2}{|c|}{ COPD } & \multirow[b]{2}{*}{$\mathrm{P}$-value } \\
\hline & No. & $\%$ & No. & $\%$ & \\
\hline Age, years & & & & & 0.694 \\
\hline$<60$ & 28 & 28.6 & 7 & 23.3 & \\
\hline $60-70$ & 39 & 39.8 & 11 & 36.7 & \\
\hline$>70$ & 31 & 31.6 & 12 & 40.0 & \\
\hline Pathological stage & & & & & 0.169 \\
\hline $\mathrm{T}_{1}-\mathrm{T}_{2}$ & 73 & 74.5 & 19 & 63.3 & \\
\hline $\mathrm{T}_{3}-\mathrm{T}_{4}$ & 25 & 25.5 & 11 & 36.7 & \\
\hline Fuhrman grade & & & & & 0.008 \\
\hline G1 & 60 & 61.2 & 9 & 30.0 & \\
\hline $\mathrm{G} 2$ & 27 & 27.6 & 13 & 43.3 & \\
\hline G3 & 11 & 11.2 & 8 & 26.7 & \\
\hline R.E.N.A.L score & & & & & 0.329 \\
\hline$\leq 8$ & 62 & 63.3 & 17 & 56.7 & \\
\hline$\geq 9$ & 36 & 36.7 & 13 & 43.3 & \\
\hline Surgical means & & & & & 0.290 \\
\hline Nephrectomy & 51 & 52.0 & 18 & 60.0 & \\
\hline Partial nephrectomy & 47 & 47.96 & 12 & 40.0 & \\
\hline Pulmonary function test & & & & & 0.002 \\
\hline Normal & 75 & 76.5 & 8 & 26.7 & \\
\hline Abnormal & 23 & 23.5 & 22 & 73.3 & \\
\hline Smoking history & & & & & $<0.001$ \\
\hline Smoking index $\leq 400$ & 76 & 77.6 & 10 & 33.3 & \\
\hline Smoking index $>400$ & 22 & 22.4 & 20 & 67.7 & \\
\hline C-reactive protein, $\mathrm{mg} / \mathrm{l}$ & & & & & $<0.001$ \\
\hline$<4.0$ & 56 & 57.1 & 7 & 23.3 & \\
\hline $4.1-10.0$ & 34 & 34.7 & 12 & 40.0 & \\
\hline$>10.0$ & 8 & 8.2 & 11 & 36.7 & \\
\hline
\end{tabular}

Serum haemoglobin, $\mathrm{g} / \mathrm{l}$

$>120$
$100-120$
$<100$

$\begin{array}{rrrr}68 & 69.4 & 14 & 46.7 \\ 21 & 21.4 & 9 & 30.0 \\ 9 & 9.2 & 7 & 23.3\end{array}$

Other comorbidities

Hypertension

Diabetes mellitus

Coronary disease

Tuberculosis

Expression of HIF-1 $\alpha$

$\begin{array}{lrrrr}- & 26 & 26.5 & 2 & 6.7 \\ + & 42 & 42.9 & 4 & 13.3 \\ ++ & 18 & 19.4 & 17 & 56.7 \\ +++ & 12 & 12.2 & 7 & 23.3\end{array}$

COPD, chronic obstructive pulmonary disease; HIF-1 $\alpha$, hypoxia inducible factor- $1 \alpha$.

COPD, may contribute to the hypoxic environment present in tumours. Lower levels of preoperative hemoglobin, higher 
Table III. Chi-square $\left(\chi^{2}\right)$ test analysis of HIF-1 $\alpha$ expression and its association with pathological stage and histological grade of tumours.

\begin{tabular}{|c|c|c|c|c|c|c|c|c|c|}
\hline \multirow[b]{2}{*}{ Expression of HIF-1 $\alpha$} & \multicolumn{4}{|c|}{ Pathological stage } & \multicolumn{5}{|c|}{ Fuhrman grade } \\
\hline & $\mathrm{T}_{1}-\mathrm{T}_{2}$ & $\mathrm{~T}_{3}-\mathrm{T}_{4}$ & $\chi^{2}$ & P-value & $\mathrm{G} 1$ & $\mathrm{G} 2$ & G3 & $\chi^{2}$ & P-value \\
\hline- & 25 & 3 & 21.97 & $<0.001$ & 22 & 5 & 1 & 20.38 & 0.002 \\
\hline+ & 39 & 7 & & & 26 & 14 & 6 & & \\
\hline++ & 21 & 14 & & & 18 & 12 & 5 & & \\
\hline+++ & 7 & 12 & & & 3 & 9 & 7 & & \\
\hline
\end{tabular}

HIF-1 $1 \alpha$, hypoxia inducible factor- $1 \alpha$.

Table IV. Significant prognostic variables on survival by univariate analysis.

\begin{tabular}{|c|c|c|c|c|c|}
\hline Variables & No. & Median OS, months & P-value & Median PFS, months & P-value \\
\hline Age, years & & & 0.076 & & 0.091 \\
\hline$<60$ & 35 & 56.2 & & 36.0 & \\
\hline $60-70$ & 50 & 60.4 & & 39.0 & \\
\hline$>70$ & 43 & 49.5 & & 32.0 & \\
\hline Pathological stage & & & $<0.001$ & & 0.002 \\
\hline $\mathrm{T}_{1}-\mathrm{T}_{2}$ & 92 & 65.1 & & 41.0 & \\
\hline $\mathrm{T}_{3-} \mathrm{T}_{4}$ & 36 & 46.2 & & 26.7 & \\
\hline Histological grade & & & 0.011 & & 0.001 \\
\hline Good & 69 & 70.6 & & 51.0 & \\
\hline Moderate & 40 & 60.4 & & 40.2 & \\
\hline Poor & 19 & 44.6 & & 21.5 & \\
\hline R.E.N.A.L score & & & $<0.001$ & & $<0.001$ \\
\hline$\leq 8$ & 79 & 69.5 & & 39.8 & \\
\hline$\geq 9$ & 49 & 43.4 & & 29.4 & \\
\hline COPD & & & 0.009 & & 0.006 \\
\hline Presence & 30 & 50.2 & & 22.2 & \\
\hline Absence & 98 & 62.5 & & 45.0 & \\
\hline Hemoglobin, g/l & & & 0.012 & & 0.035 \\
\hline$>120 \mathrm{~g} / 1$ & 82 & 66.4 & & 53.6 & \\
\hline $100-120 \mathrm{~g} / 1$ & 30 & 54.1 & & 38.0 & \\
\hline$<100 \mathrm{~g} / \mathrm{l}$ & 16 & 43.5 & & 24.2 & \\
\hline C-reactive protein & & & 0.011 & & $<0.001$ \\
\hline$<4.0 \mathrm{mg} / 1$ & 63 & 68.2 & & 49.1 & \\
\hline $4.1-10.0 \mathrm{mg} / \mathrm{l}$ & 46 & 57.6 & & 34.0 & \\
\hline$>10.0 \mathrm{mg} / \mathrm{l}$ & 19 & 46.1 & & 26.4 & \\
\hline Expression of HIF-1 $\alpha$ & & & 0.001 & & $<0.001$ \\
\hline- & 28 & 71.2 & & 51.0 & \\
\hline+ & 46 & 62.5 & & 42.5 & \\
\hline++ & 35 & 54.2 & & 30.2 & \\
\hline+++ & 19 & 42.1 & & 20.5 & \\
\hline
\end{tabular}

COPD, chronic obstructive pulmonary disease; HIF-1 $\alpha$, hypoxia inducible factor-1 $\alpha$; OS, overall survival; PFS, progression free survival.

HIF-1 $\alpha$ expression and COPD diagnosis were identified in the present study to indicate poor prognosis in patients with ccRCC.
Anemia is defined as a lack of sufficient red blood cells to maintain adequate tissue oxygenation, and is a common comorbidity of solid tumours. Renal cancer-associated anemia 
Table V. Multivariate Cox proportional hazard model of variables associated with prognosis.

\begin{tabular}{lccr}
\hline Variables & Hazard ratio & $95 \%$ CI & P-value \\
\hline Pathological stage & & & \\
OS & 4.306 & $2.316-8.003$ & $<0.001$ \\
PFS & 3.061 & $1.703-5.502$ & 0.002 \\
R.E.N.A.L score & & & \\
OS & 6.204 & $3.556-10.830$ & $<0.001$ \\
PFS & 2.651 & $1.623-4.330$ & 0.001 \\
COPD & & & \\
OS & 2.106 & $1.197-3.706$ & 0.015 \\
PFS & 2.230 & $1.255-3.965$ & 0.001 \\
Serum haemoglobin, g/l & & & \\
OS & 1.517 & $0.812-2.837$ & 0.005 \\
PFS & 2.250 & $1.39-4.087$ & 0.013 \\
Expression of HIF-1 $\alpha$ & & & \\
OS & 1.775 & $1.109-2.841$ & 0.018 \\
PFS & 1.974 & $1.226-3.179$ & 0.002 \\
\hline
\end{tabular}

OS, overall survival; PFS, progression free survival; COPD, chronic obstructive pulmonary disease; CI, confidence interval.
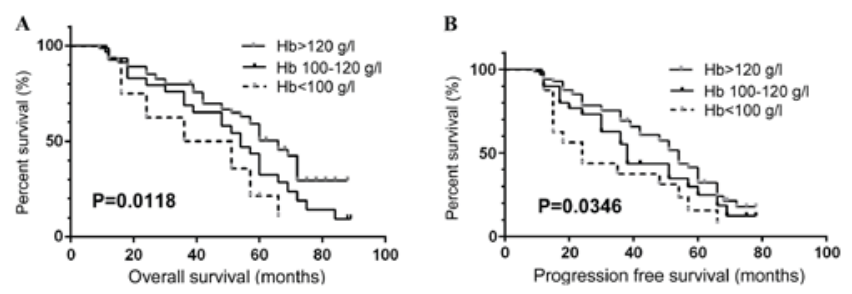

Figure 1. Kaplan-Meier survival curves of 128 renal cell carcinoma cases stratified by serum hemoglobin. (A) Overall survival and serum hemoglobin levels. (B) Progression free survival and serum hemoglobin levels. $\mathrm{Hb}$, hemoglobin.

is associated with multiple mechanisms of causation, including iatrogenic or intrinsic blood loss, cancer-associated nutritional deficiencies and bone marrow failure due to tumor encroachment (17). The levels of peripheral serum hemoglobin indicate the degree of anemia in patients with ccRCC. Patients with a lower preoperative level of serum hemoglobin are associated with a higher stage of cancer at diagnosis, and a poor prognosis even following surgery $(18,19)$. A meta-analysis including 949,445 patients concluded that preoperative anemia was associated with increased mortality, infection and acute kidney injury in patients following surgery (20). The retrospective results of the present study additionally indicated that lower preoperative hemoglobin levels were associated with shorter OS and PFS, and may be an independent prognostic variable in ccRCC patients.

COPD is a common public health problem, and it is estimated that it will rank 3rd in terms of mortality and 5th in terms of disease burden worldwide by 2020 (21). COPD is a preventable and manageable disease, characterized by persistent airflow limitation (22). Cigarette smoking is one of the best-studied
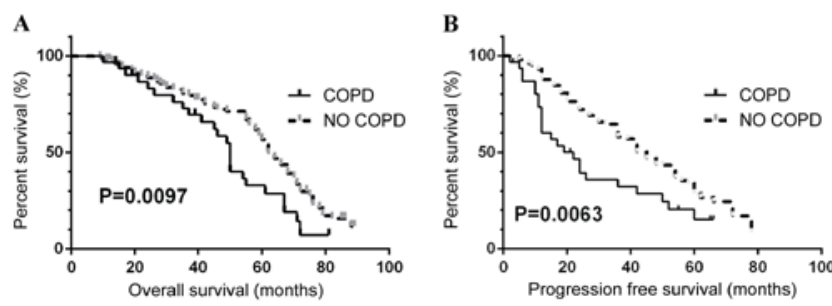

Figure 2. Kaplan-Meier survival curves of 128 renal cell carcinoma cases stratified by COPD. (A) Overall survival and COPD diagnosis. (B) Progression free survival and COPD diagnosis. COPD, chronic obstructive pulmonary disease.
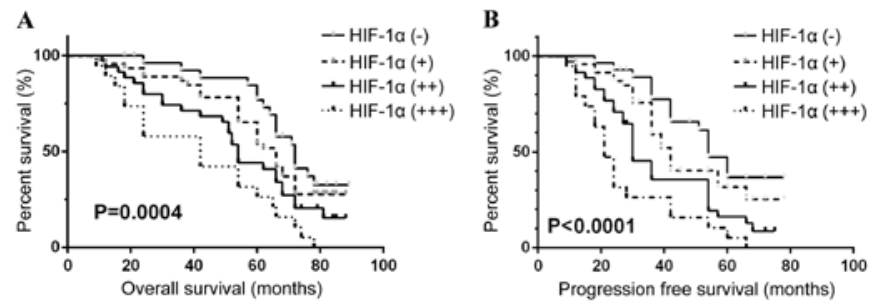

Figure 3. Kaplan-Meier survival curves of 128 renal cell carcinoma cases stratified by HIF-1 $\alpha$ expression. (A) Overall survival and HIF-1 $\alpha$ expression. (B) Progression free survival and HIF-1 $\alpha$ expression. HIF-1 $\alpha$, hypoxia inducible factor- $1 \alpha$.

risk factors for COPD, which in turn contributes to tumor invasion ability and poor prognosis in ccRCC (23). Previous studies have indicated that COPD is an independent poor prognostic factor, and a high-risk factor for postoperative recurrence in patients with lung tumors $(24,25)$. However, the underlying mechanisms are yet to be elucidated. A possible hypothesis is that COPD alters the immunological status of patients, leading to systemic disease including cachexia, cardiovascular disease, osteoporosis and diabetes, and such comorbidities may lead to poor patient prognosis (26). Furthermore, previous studies have showed that COPD status was associated with high HIF-1 $\alpha$ expression, which was a critical factor responsible for maintaining oxygen homeostasis in hypoxic conditions and a potential marker for the prognosis of various types of cancer $(27,28)$. The present study demonstrated that smoking history and COPD diagnosis have a significant contribution to the OS and PFS of patients with ccRCC.

The heterodimer transcription factor HIF-1 was first detected in 1991 as a regulator of renal erythropoietin production (29). HIF-1 $\alpha$ is a subunit of HIF, which is expressed at significantly higher levels in cancer anabolism. In hypoxic conditions, HIF- $1 \alpha$ has a central function in cellular and systemic oxygen homeostasis, inducing the transcription of $>60$ proteins (30). The biological functions of HIF-1 $\alpha$ are regulated by post-translational modifications, including phosphorylation, ubiquitination, hydroxylation and acetylation. In normoxic conditions, HIF-1 $\alpha$ is degraded through the ubiquitin-proteasome pathway, due to the hydroxylation of proline and lysine residues in the oxygen-dependent degradation domain. When HIF-1 $\alpha$ becomes stable and active, it is essential for the regulation of tumor-associated gene expression (30). Dimerization of HIF- $1 \alpha$ and HIF-1 $\beta$ in hypoxic conditions results in the formation of the HIF-1 
transcription factor, which translocates to the nucleus to bind to hypoxia response elements and activate the transcription of oxygen-dependent genes (31).

In hypoxic conditions, the rapid proliferation of cancer cells and tumor vasculature abnormalities lead to an imbalance between oxygen delivery and consumption. Activation of HIF-1 $\alpha$ is essential in regulating the adaptive responses of tumor cells. HIF-1 $\alpha$ aids in tumor survival and progression by shifting the metabolism towards glycolysis, inducing angiogenesis, regulating apoptosis and inducing tumor migration (32).

The importance of HIF- $1 \alpha$ in ccRCC remains controversial, although numerous studies have demonstrated that HIF-1 $\alpha$ promotes tumorigenesis, metastasis, and chemotherapy and radiotherapy resistance in ccRCC $(33,34)$. HIF-1 $\alpha$ may be associated with the functioning of the Von Hippel-Lindau (VHL) gene in ccRCC, and VHL function, in turn, is closely associated with ccRCC incidence. In normoxic conditions, HIF-1 $\alpha$ and $-2 \alpha$ are degraded by the VHL-associated protein, a member of the E3 ubiquitin ligase complex (33). VHL-associated proteolysis of HIF-1 $\alpha$ and $2 \alpha$ is disrupted in patients with an inhibited VHL gene or congenital defect, resulting in elevated HIF-1 $\alpha$ and $2 \alpha$ expression, contributing to the progression and poor prognosis of ccRCC. Razorenova et al (35) demonstrated that HIF-1 $\alpha$ expression was associated with ccRCC tumorigenesis and proliferation, whereas Gudas et al (36) demonstrated the function of HIF-1 $\alpha$ as a tumor suppressor in ccRCC. Therefore, the involvement of HIF-1 $\alpha$ in ccRCC is complex and the precise function of HIF-1 $\alpha$ in ccRCC is not completely understood (37). In the present study, elevated HIF-1 $\alpha$ expression in ccRCC was associated with higher pathological stage or histological grade, in addition to a reduction in OS and PFS.

ccRCC is the most common type of RCC. Diagnosed patients may have hypoxic tumor conditions, anemia and/or COPD, all contributing to a poor prognosis. Elevated HIF-1 $\alpha$ levels indicate a more advanced cancer stage and reduced survival in ccRCC patients. Thus, HIF-1 $\alpha$ may be a potential ccRCC biomarker, and hypoxic conditions may be corrected in order to prevent and treat ccRCC.

\section{Acknowledgements}

The present study was supported by the grant from Science and Technology Agency of Hunan Province (no. 2016JJ3178) and Finance Department of Hunan Province (2016-129). The funders had no role in the study design, data collection and analysis, decision to publish, or preparation of the manuscript.

\section{References}

1. Siegel RL, Miller KD and Jemal A: Cancer statistics, 2017. CA Cancer J Clin 67: 7-30, 2017.

2. Thakur A and Jain SK: Kidney cancer: Current progress in treatment. World J Oncol 2: 158-165, 2011.

3. Ferlay J, Soerjomataram I, Dikshit R, Eser S, Mathers C, Rebelo M, Parkin DM, Forman D and Bray F: Cancer incidence and mortality worldwide: Sources, methods and major patterns in GLOBOCAN 2012. Int J Cancer 136: E359-E386, 2015.

4. Liu WS, Liu YD, Fu Q, Zhang WJ, Xu L, Chang Y and Xu JJ: Prognostic significance of ubiquinol cytochrome c reductase hinge protein expression in patients with clear cell renal cell carcinoma. Am J Cancer Res 6: 797-805, 2016.

5. Lu X and KangY: Hypoxia and hypoxia-inducible factors: Master regulators of metastasis. Clin Cancer Res 16: 5928-5935, 2010.
6. Nallamshetty S, Chan SY and Loscalzo J. Hypoxia: A master regulator of microRNA biogenesis and activity. Free Radic Biol Med 64: 20-30, 2013.

7. Huang Z, Xu R, Lv C, Zhong Z, Zhang L, Zhu L, Tang Y and Zhao X: A chronic obstructive pulmonary disease negatively influences the prognosis of patients with bladder urothelial carcinoma via hypoxia inducible factor- $1 \alpha$. Int J Clin Exp Med 7: 3344-3353, 2014.

8. Masoud GN and Li W: HIF-1 $\alpha$ pathway: Role, regulation and intervention for cancer therapy. Acta Pharm Sin B 5: 378-389, 2015.

9. Ke QD and Costa M: Hypoxia-inducible factor-1 (HIF-1). Mol Pharmacol 70: 1469-1480, 2006.

10. Powis G and Kirkpatrick L: Hypoxia inducible factor-1alpha as a cancer drug target. Mol Cancer Ther 3: 647-654, 2004.

11. Kong CC and Dai AG: Expression of mitogen-actived protein kinase, phosphatidylinositol 3-kinase and hypoxia-inducible factor-1alpha in pulmonary arteries of patients with chronic obstructive pulmonary disease. Zhonghua Jie He He Hu Xi Za Zhi 29: 372-375, 2006 (In Chinese).

12. Spaliviero M, Poon BY, Aras O, Di Paolo PL, Guglielmetti GB, Coleman CZ, Karlo CA, Bernstein ML, Sjoberg DD, Russo P, et al: Interobserver variability of R.E.N.A.L., PADUA, and centrality index nephrometry score systems. World J Urol 33: 853-858, 2015.

13. Bellmunt J, Puente J, Garcia de Muro J, Lainez N, Rodríguez C and Duran I; Spanish Society for Medical Oncology: SEOM clinical guidelines for the treatment of renal cell carcinoma. Clin Transl Oncol 16: 1043-1050, 2014

14. Zhang C, Li X, Hao H, Yu W, He Z and Zhou L: The correlation between size of renal cell carcinoma and its histopathological characteristics: A single center study of 1867 renal cell carcinoma cases. BJU Int 110: E481-E485, 2012.

15. Zhong H, De Marzo AM, Laughner E, Lim M, Hilton DA, Zagzag D, Buechler P, Isaacs WB, Semenza GL and Simons JW: Overexpression of hypoxia-inducible factor 1alpha in common human cancers and their metastases. Cancer Res 59: 5830-5835, 1999.

16. Harris AL: Hypoxia-a key regulatory factor in tumour growth. Nat Rev Cancer 2: 38-47, 2002.

17. Spivak JL: Cancer-related anemia: Its causes and characteristics. Semin Oncol 21 (2 Suppl 3): S3-S8, 1994

18. Dunne JR, Gannon CJ, Osborn TM, Taylor MD, Malone DL and Napolitano LM: Preoperative anemia in colon cancer: Assessment of risk factors. Am Surg 68: 582-587, 2002.

19. Richards T, Musallam KM, Nassif J, Ghazeeri G, Seoud M, Gurusamy KS and Jamali FR: Impact of preoperative anaemia and blood transfusion on postoperative outcomes in gynaecological surgery. PLoS One 10: e0130861, 2015.

20. Fowler AJ, Ahmad T, Phull MK, Allard S, Gillies MA and Pearse RM: Meta-analysis of the association between preoperative anaemia and mortality after surgery. Br J Surg 102: 1314-1324, 2015

21. Vestbo J, Hurd SS, Agustí AG, Jones PW, Vogelmeier C, Anzueto A, Barnes PJ, Fabbri LM, Martinez FJ, Nishimura M, et al: Global strategy for the diagnosis, management, and prevention of chronic obstructive pulmonary disease: GOLD executive summary. Am J Respir Crit Care Med 187: 347-365, 2013

22. Bettoncelli G, Blasi F, Brusasco V, Centanni S, Corrado A, De Benedetto F, De Michele F, Di Maria GU, Donner CF, Falcone F, et al: The clinical and integrated management of COPD. Sarcoidosis Vasc Diffuse Lung Dis 31 (Suppl 1): S3-S21, 2014.

23. Ishida M, Mikami S, Shinojima T, Kosaka T, Mizuno R, Kikuchi E, Miyajima A, Okada Y and Oya M: Activation of aryl hydrocarbon receptor promotes invasion of clear cell renal cell carcinoma and is associated with poor prognosis and cigarette smoke. Int J Cancer 137: 299-310, 2015.

24. Qiang G, Liang C, Xiao F, Yu Q, Wen H, Song Z, Tian Y, Shi B, Guo Y and Liu D: Impact of chronic obstructive pulmonary disease on postoperative recurrence in patients with resected non-small-cell lung cancer. Int J Chron Obstruct Pulmon Dis 11: 43-49, 2015.

25. Yoshida Y, Kage H, Murakawa T, Sato Y, Ota S, Fukayama M and Nakajima J: Worse prognosis for stage IA lung cancer patients with smoking history and more severe chronic obstructive pulmonary disease. Ann Thorac Cardiovasc Surg 21: 194-200, 2015. 
26. Sin DD, Anthonisen NR, Soriano JB and Agusti AG: Mortality in COPD: Role of comorbidities. Eur Respir J 28: 1245-1257, 2006.

27. Schultz K, Fanburg BL and Beasley D: Hypoxia and hypoxia-inducible factor-1alpha promote growth factor-induced proliferation of human vascular smooth muscle cells. Am J Physiol Heart Circ Physiol 290: H2528-H2534, 2006.

28. Wei WT, Li B, Chen M, Jia HR and Zhang HX: Associations between HIF-1 $\alpha$ polymorphisms C1772T and G1790A and susceptibility to chronic obstructive pulmonary disease. Genet Mol Res 14: 17341-17347, 2015.

29. Semenza GL and Wang GL: A nuclear factor induced by hypoxia via de novo protein synthesis binds to the human erythropoietin gene enhancer at a site required for transcriptional activation. Mol Cell Biol 12: 5447-5454, 1992.

30. Lee JW, Bae SH, Jeong JW, Kim SH and Kim KW: Hypoxia-inducible factor (HIF-1) alpha: Its protein stability and biological functions. Exp Mol Med 36: 1-12, 2004.

31. Zimna A and Kurpisz M: Hypoxia-inducible factor-1 in physiological and pathophysiological angiogenesis: Applications and therapies. Biomed Res Int 2015: 549412, 2015.
32. Ajduković J: HIF-1- $\alpha$ big chapter in the cancer tale. Exp Oncol 38: 9-12, 2016.

33. Gudas LJ, Fu L, Minton DR, Mongan NP and Nanus DM: The role of HIF1 $\alpha$ in renal cell carcinoma tumorigenesis. J Mol Med (Berl) 92: 825-836, 2014.

34. Rankin EB and Giaccia AJ: Hypoxic control of metastasis. Science 352: 175-180, 2016.

35. Razorenova OV, Castellini L, Colavitti R, Edgington LE, Nicolau M, Huang X, Bedogni B, Mills EM, Bogyo M and Giaccia AJ: The apoptosis repressor with a CARD domain (ARC) gene is a direct hypoxia-inducible factor 1 target gene and promotes survival and proliferation of VHL-deficient renal cancer cells. Mol Cell Biol 34: 739-751, 2014

36. Gudas LJ, Fu L, Minton DR, Mongan NP and Nanus DM: The role of HIFl $\alpha$ in renal cell carcinoma tumorigenesis. J Mol Med (Berl) 92: 825-836, 2014.

37. Nanus DM and Gudas LJ: The tale of two hypoxia-inducible factors in renal cell carcinoma. Eur Urol 69: 658-659, 2016. 